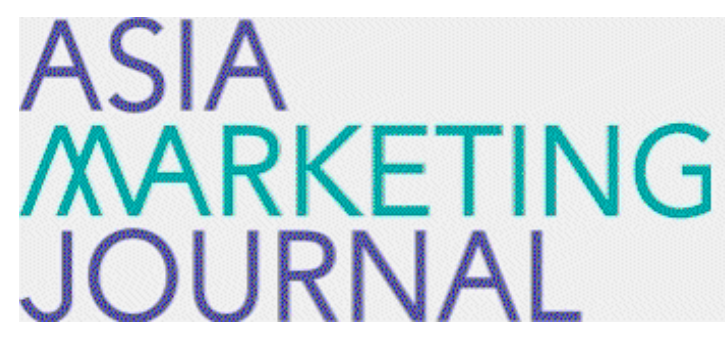

ASIA MARKETING JOURNAL

Volume 20 | Issue 4

Article 2

$1-31-2019$

\title{
The Synergy Effect of a Corporate-Level Loyalty Program Integration on Customer Equity
}

Dae-Yun Park

Shijin Yoo

Follow this and additional works at: https://amj.kma.re.kr/journal

Part of the Marketing Commons

\section{Recommended Citation}

Park, Dae-Yun and Yoo, Shijin (2019) "The Synergy Effect of a Corporate-Level Loyalty Program Integration on Customer Equity," Asia Marketing Journal: Vol. 20 : Iss. 4 , Article 2.

Available at: https://doi.org/10.15830/amj.2019.20.4.21

This Article is brought to you for free and open access by Asia Marketing Journal. It has been accepted for inclusion in Asia Marketing Journal by an authorized editor of Asia Marketing Journal. 


\title{
The Synergy Effect of a Corporate-Level Loyalty Program Integration on Customer Equity*
}

\author{
Dae-Yun Park ${ }^{* *}$ \\ Shijin Yoo***
}

\begin{abstract}
This study empirically examines the synergy effect of a corporate-level loyalty program on customer equity (CE) known as the lifetime value of current and future customers (Blattberg et al. 2009). A corporate-level loyalty program refers to a company-wide integration loyalty program at the corporate-level in which subsidiaries (multi-divisions) participate as program members. It does not merely examine whether there is an integration effect of a corporate-level loyalty program from the CE perspective, but it provides practical implications for a firm's strategic focus by identifying which value creation channels (i.e., acquisition, retention, and cross-selling), brand characteristics (i.e., size of the customer base before integration, diversity of products, and sales channel type), and consumer characteristics (i.e., customer relationship stage, transaction amount before integration, transaction period, and number of purchased brands) are affected the most by the synergy effect.
\end{abstract}

Key words: Loyalty Program, Customer Equity, Customer Acquisition, Customer Retention, Cross-selling, Partnership

\section{Introduction}

Strategic alliances have been known to be effective in complementing competences between partners, creating economies of scale, developing new target markets, and securing new customers (e.g., Avery, Steenburgh, Deighton, and Caravella 2012; Chatterjee 2012). In the area of loyalty programs, strategic alliances have been actively applied in partnership-based forms. Partnershipbased loyalty programs can be divided into a

\footnotetext{
* This research is supported by BK21PLUS Research Fund for Korea University Business School.

** BK21PLUS Research Professor (Asian Hub for Global Business Research), Korea University Business School (daeyun@korea.ac.kr)

*** Professor of Marketing, Korea University Business School (shijinyoo@korea.ac.kr)
} 
multi-firm partnership program, a multi-firm alliance program, a coalition program, and a corporate-level integration program depending on the structure of the partnership (De Wulf et al. 2008; Dorotic, Fork, and Verhoef 2011; Frisou and Yildiz 2011; Hwang et al. 2016). 〈Table 1〉 shows the characteristics and examples of each program. Of the four types of partnerships, a multi-firm partnership program, a multi-firm alliance program, and a coalition program are inter-firm partnerships with interfirm network ties, whereas a corporate-level integration program is an intra-firm partnership with intra-firm network ties (Walter, Lechner, and Kellermanns 2007). While the goal of an inter-firm partnership program is maximizing performance from the perspective of each brand that participates in the partnership, the goal of an intra-firm partnership program is maximizing performance at the corporate-level rather than at the individual brand level. For example, in a multi-firm partnership program, the core brand builds a partnership with multiple brands to improve customer service. Therefore, it is important to consider what partners are more effective in producing such results for the core brand and how such partnerships improve the core brand's performance (e.g., Lemon and Wangenheim 2009). A partnership program, with multiple brands that are also potential competitors within the same industry, has difficulty achieving equivalent results for all brands that participate within a limited market.
Considering this, the focus is on analyzing what brands obtain greater benefits by participating in the partnership network, and what plans are needed to maximize such performance (e.g., Liu and Yang 2009). Affiliated brands of a coalition program participate as markets to earn and redeem points, thereby adding program members as new customers and potentially turning them into regular customers. Thus, attention is paid to comparatively assess whether it is more effective to participate as an affiliate to acquire new customers or maintain relationships, or to independently manage a program (e.g., Lee, Song, and Kim 2012). However, a corporatelevel integration program, which is an intrafirm partnership, puts greater emphasis on understanding the synergy effects at the corporate-level rather than the individual performance of each brand, differences in contribution by brand, and how the brands complement one another through integration. Yet, there has been a good deal of research thus far on multi-firm partnership programs, multi-firm alliance programs and coalition programs, which established the grounds to understand program effects and mechanisms. On the other hand, a company-wide loyalty program is difficult to understand the synergy effects, as well as the theoretical mechanisms of the channels through which such effects are produced due to insufficient empirical research.

This study aims to examine the synergy effects of corporate-level integration programs 
to supplement existing research limitations and present future research directions. The empirical analysis was conducted on a corporate-level integrated loyalty program of a company in South Korea that had integrated their loyalty programs, previously independently managed by different business areas in the company. The major theoretical / practical expected contributions can be summarized as follows. First, by examining the synergy effect of a corporate-level integration program that has not been studied before, this study contributes to the development of relevant research by analyzing whether an integrated synergy effect anticipated by a firm is actually produced. Second, this study examines whether there is an integration effect of company-wide loyalty programs from the customer equity (CE) perspective, and if there is, what channel contributes the most. An empirical analysis of the CE creation channels of a corporate-level integration program is especially important in that it fully examines the relationship between marketing activities and the $\mathrm{CE}$ creation channels, customer acquisition (ACQ) - customer retention (RET) - cross-selling (CRS), which have previously been presented only conceptually, as well as a foundation for a theory of a potential CE maximization channel for corporatelevel integration programs. Third, this study examines the characteristics of brands and consumers that contribute to the integrated synergies of corporate-level integration programs by diversifying the level of analysis to the corporate-level as well as brand and consumer level. To begin with, at the brand level

〈Table 1〉 Typology of loyalty program partnerships

\begin{tabular}{|c|c|c|c|}
\hline Type & Ownership & Partnership & Examples \\
\hline $\begin{array}{l}\text { Multi-firm partnership } \\
\text { program }\end{array}$ & $\begin{array}{l}\text { - The focal firm that } \\
\text { owns the LP }\end{array}$ & $\begin{array}{l}\text { - Across-sector } \\
\text { - Complementary or } \\
\text { competitive relations }\end{array}$ & $\begin{array}{l}\text { - AT\&T Thanks } \\
\text { - Amtrak Guest Rewards }\end{array}$ \\
\hline $\begin{array}{l}\text { Multi-firm alliance } \\
\text { program }\end{array}$ & $\begin{array}{l}\text { - All partners who } \\
\text { join the LP }\end{array}$ & $\begin{array}{l}\text { - Within-sector } \\
\text { - Complementary relations }\end{array}$ & $\begin{array}{l}\text { - Star Alliance (Global) } \\
\text { - Skyteam (Global) } \\
\end{array}$ \\
\hline Coalition program & $\begin{array}{l}\text { - The third party } \\
\text { that operates the } \\
\text { LP }\end{array}$ & $\begin{array}{l}\text { - Across-sector } \\
\text { - Complementary and } \\
\text { competitive relations } \\
\text { - Affiliate network }\end{array}$ & $\begin{array}{l}\text { - } \text { Nectar (UK) } \\
\text { - Payback (Germany) } \\
\text { - Air Miles (Canada) } \\
\text { - FlyBuys (Australia) } \\
\text { - OK Cashbag (Korea) } \\
\text { - T-Point (Japan) } \\
\text { - China Rewards (China) }\end{array}$ \\
\hline $\begin{array}{l}\text { Company-wide } \\
\text { integration program }\end{array}$ & $\begin{array}{l}\text { - The holding } \\
\text { company }\end{array}$ & $\begin{array}{l}\text { - Across-sector } \\
\text { - Complementary relations } \\
\text { - Subsidiary network }\end{array}$ & $\begin{array}{ll} & \text { Sears (US) } \\
\text { - Marriott (US) }\end{array}$ \\
\hline
\end{tabular}


characteristics are divided into 1) size of the customer base before integration, 2) diversity of products, and 3) sales channel type (offline stores vs. online shopping mall) to examine the differences in contribution among brands in terms of the integration effect. The consumer level divides customers into new and existing and examines consumer roles in the integration effect using two methods: a comparison of the differences in synergy effects and a regression analysis of the relationship between an individual's propensity to consume (e.g., transaction amount before integration, transaction period, number of usage brands, etc.) and CE.

\section{Research framework}

\subsection{Customer equity and its creation channels}

Rust, Lemon, and Zeithaml (2004, p. 110) defines Customer Equity (CE) as "the total of the discounted lifetime values summed over all of the firm's current and potential customers". Typical theoretical frameworks that present the components and processes of the $\mathrm{CE}$ are the RLZ model (Rust, Lemon, and Zeithaml (2000)) and the BGT model (Blattberg, Getz, and Thomas (2001)). The RLZ model considers $\mathrm{CE}$ to include the Value equity - Brand equity - and Relationship equity, while the BGT model considers $\mathrm{CE}$ to be the sum of the Acquisition Value (ACQ) - Retention Value (RET) - and Cross-selling Value (CRS). Of the two, this study will use the BGT model to examine the relationship between the corporatelevel integration program and $\mathrm{CE}$ creation channels. The RLZ perspective does nothing more than merely present the loyalty program as one of the marketing programs that create relational assets, whereas the BGT perspective examines the formation process of $\mathrm{CE}$ from the perspective of the customer relationship process. Thus, it is appropriate in gaining an understanding of what specific mechanisms of the corporate-level integration program affects CE. As in this study, many other studies have already been conducted with regard to the BGT model to examine the relationship between a firm's specific marketing activity and $\mathrm{CE}$ (Bolton, Lemon, and Verhoef 2004; Gupta and Zeithaml 2006; Gupta et al.2006).

Previous studies that measured the effects of loyalty programs at the corporate-level have mostly focused on the firm's financial performance such as sales, profitability, or market share (Kopalle and Neslin 2003; Lal and Bell 2003; Liu and Yang 2009). However, considering that loyalty programs are long-term marketing programs to enhance customer loyalty and profitability by offering rewards for customers' repeat purchases (Johnson 1998; Yi and Jeon 2003), loyalty program performance measurement from the $\mathrm{CE}$ perspective is highly significant. 
$\mathrm{CE}$, which is a financial value that measures customers' contributions to a firm, is an important performance indicator that determines the ROI (return on investment) of the loyalty program (Furinto, Pawitra, and Balqiah 2009). Moreover, considering the fact that $\mathrm{CE}$ is created through the sum of ACQ-RET-CRS, it is necessary to understand the relationship between integrated loyalty programs and these $\mathrm{CE}$ creation channels (ACQ-RET-CRS) beyond merely determining whether loyalty programs affect CE. Bick (2009) emphasized that if the firm strategy from the perspective of building brand equity is STP (Segmentation, Targeting, and Positioning), then the strategy from the perspective of building customer equity is ARC (Acquisition, Retention, and Cross-selling). By assessing how an integrated program contributes to each $\mathrm{CE}$ creation channel, it will be possible to provide practical implications for a firm's strategic focus.

Based on the BGT model, ACQ is defined as the payment amount of the first transaction made after joining the program, RET is defined as the financial value that contributes to the brands participating in the program (measured by the CLVs of each participating brand), and CRS is defined as the sum of the financial values that contribute to all other brands in the loyalty program, measured by the CLVs of all the other brands. Hence, Formula (1) equates to $\mathrm{CLV}$ for each individual and $\mathrm{CE}$ at the brand level is the sum of the values of ACQ, RET, and CRS for the relevant brand such as
Formula (2). Finally, CE at the corporatelevel is the sum of the values of ACQ, RET, and CRS for individual customers, as shown in Formula (3).

$$
\begin{aligned}
& C L V_{i}=A C Q_{i j}+R E T_{i j}+C R S_{i k} \\
& i: \text { households }(1, \ldots, n) \\
& C L V_{i}: i^{\prime} \text { s lifetime value } \\
& A C Q_{i j}: i^{\prime} \text { s profitability at the first purchase time } \\
& \quad \text { for the first purchse brand } j \text { among brands } k \\
& R E T_{i j}: i^{\prime} s \text { CLV for the first purchase brand } j-A C Q_{i j} \\
& C R S_{i k}: i^{\prime} s \text { lifetime value for all brands } k \text { other than } \\
& \text { the first - purchase brand } j
\end{aligned}
$$$$
C E_{j}=\sum_{i=1}^{n} A C Q_{i j}+\sum_{i=1}^{n} R E T_{i j}+\sum_{i=1}^{n} C R S_{i j}
$$

$$
j: \operatorname{brands}(1, \ldots, k)
$$

$\mathrm{CE}_{j}$ : customer equity at each brand $j$ level

$A C Q_{i j}$ : the sum of $i^{\prime} s$ profitability at the first purchase time for the first purchase brand $j$

$R E T_{i j}$ : the sum of $i^{\prime}$ S CLV for the first purchase brand $j-A C Q_{1 i j}$

$C R S_{i j}$ : the sum of $i^{\prime} s C L V$ for the brands $j$ that has the first purchase at brand $k$

$$
C E_{l}=\sum_{j=1}^{k} A C Q_{j}+\sum_{j=1}^{k} R E T_{j}+\sum_{j=1}^{k} C R S_{j}
$$

$$
\begin{aligned}
& \mathrm{CE}_{l}: \text { customer equity at the corporate level } \\
& A C Q_{l}: \text { the sum of acquisition value of each brand } j \\
& R E T_{l}: \text { the sum of retention value of each brand } j \\
& C R S_{l} \text { : the sum of cross - selling value of each brand } j
\end{aligned}
$$




\subsection{The effect of a corporate-level integration program on $\mathrm{CE}$}

A corporate-level integration program is actively implemented by firms to promote business diversification strategies. They pay attention to corporate-level integration programs for two reasons. First, such a program is attractive in that it gathers each department's customers into a single platform called integrated loyalty program, becomes a medium that increases each department's market potential by accelerating cross-purchasing among brands, and acts as a symbiotic marketing tool that maximizes performance at the corporate-level (Varadarajan and Daniel 1986). Second, from the perspective of knowledge management, the program links the consumption patterns and demographic data of customers of each brand, and even consumer behavior, by various media such as the Internet, mobile devices, and SNS (Social Network Services). In that sense, the program has a significantly high value for practical use in that it provides an opportunity to create extensive customer knowledge incomparable to the fragmentary knowledge that had been determined by transaction records individually collected by each brand. Theoretically, research on company-wide loyalty integration programs has significance in that it provides an opportunity to examine the synergy mechanisms of firms that implement business customer diversification strategies. This is because previous studies that focused on the synergy effects of business diversification strategies mostly explain the cause of such synergies from the organizational perspective as resource sharing from a resource based view (e.g., Rumelt 1982; Marciukaityte, Roskelley, and Wang 2009). Company-wide loyalty integration programs can track how synergy is produced among business departments, through customer interactions with each brand, when multiple departments of the diversified firm cooperate on a marketing or loyalty program. For example, examining the cause of a company-wide sales increase from the corporate-level integration program shows that the corporate-level sales increased along with a rise in purchase quantities of Brand A customers of other department brands, or consumer purchases of Brand B had a positive effect on purchases of Brand $\mathrm{C}$ in the following period, which all contributed to the company-wide sales increase. Such observations of consumer behavior cannot be easily verified by previous studies from an organizational perspective. Therefore, the integration of the loyalty program will have a positive impact on the increase in customer equity.

While customer acquisition, retention, and cross-selling will all have positive effects on customer equity growth in the integration program, we expect that the impact of cross-selling will be greatest. By integrating the points earned, this type of program structurally facilitates consumer transactions among brands, after 
which synergy effects (where the customers of one brand become new customers of another) are produced owing to this structure. Evanschitzky et al. (2012) argued that customers' adherence to a loyalty program is influenced by social benefits from the relationship with the firm, program value, and member special treatment, whereas loyalty to the firm is influenced by engagement, trust, and firm satisfaction.

\subsection{The effect of a corporate-level integration program on customer acquisition}

If an integrated loyalty program includes multiple brands within a single program network rather than independently operating brand loyalty programs, and thereby increases perceived utility of the program, this will lead to a positive impact on the participation rate of new customers. As Lara and de Madariaga (2007) and Bijmolt, Dorotic, and Verhoef (2011) explained that loyalty programs in the form of partnerships increase potential benefits and decrease cognitive costs, the integration of programs enables customers to simultaneously use multiple brands with a single membership card. This increases the potential benefits of facilitating the earning, redemption, and management of points compared with points earned from stand-alone brand programs. On the other hand, the program operation scale increases and leads to the expectation those firms will make more systematic investments, and thus better systematically manage personal information than a single small-scale program, which will play the role of reducing cognitive costs of the program. Therefore, there will be an acquisition effect that adds not only customers that have already joined the brand programs, but also customers that have not participated in the stand-alone brand programs as well as customers that have been using competitor brands.

Second, the financial value at the point of participation represents the value of contribution by customers to the firm at the point of their first transactions. This provides information on the payment amounts made by the customers in their first transactions, and can be used in making decisions about acquisition costs using such input. When a single brand operates its own stand-alone loyalty program, customers join the program in a biased manner, focusing on a brand they believe has a high utility among many competing brands. However, after integration, they end up joining a corporate-wide program, regardless of which brand they had chosen in the first place, and thus the contribution value at the point of acquisition after integration becomes closer to the average purchase amount of all the brands. For example, if the average purchase amount of the main channel brand had been significantly low before integration, it would increase after integration (move closer to the average). According to Frisou and 
Yildiz (2011), consumers participating in loyalty programs tend to be engaged in rational consumption that can maximize utility from a long-term perspective rather than maximizing short-term utility, and also tend to add to the initial expenditure level to achieve the redemption of the rewards they expect. Thus, this may also be a factor that increases the contribution value at the point of acquisition.

Finally, ACQ can be measured by the CE of a new customer group created during a certain time period. That is, from a segmentation perspective the financial value created by separating new customers from existing customers. The value of new customers will increase postintegration compared to pre-integration. Since all the brands are managed independently before integration, customers tend to make transactions at the specific brand they preferred. However, after integration, there is a motivation to use multiple brands within the network in order to acquire rewards through the program.

\subsection{The effect of a corporate-level integration program on customer retention}

RET, a key channel for CE creation, can be examined by assessing the retention rate of existing customers and the financial value created by existing customers. Previous studies explain that the strategic alliances of integrated loyalty programs have greater value than single stand-alone programs. This is due to benefits the firm gains by maximizing value propositions to customers, providing more diversified services compared to programs independently managed (Bolton, Kannan, and Bramlett 2000), and benefits customers by allowing them to earn points through multiple brands, accelerating the point of reward acquisition, while also broadening the scope of the brands to redeem points and gain rewards (Berman 2006: Capizzi and Ferguson 2005). Considering the fact that the corporate-level integration program is also a partnership of multiple brands, the characteristics of such partnership programs can be applied equally to corporate-level integration programs. Moreover, dissatisfaction in the customer preferred brand has a direct influence on customer churn from a program or brand in single brand programs. However, in a corporate-level integration program, even if there is dissatisfaction in a certain brand within the network, the firm can retain the customer relationship through transactions with other brands in the network as long as the utility of the program is high. Thus, there will be customer churn from the dissatisfactory brand, but the customers can be retained at the corporate-level. Therefore, there is a high possibility of an increase in customer retention rate at the corporate-level with an integrated program compared to a single, independently managed program. However, it is uncertain whether the financial value of customer retention will further increase after integration since the 
motivation to purchase repeatedly from the same brand is lower once the scope of options to earn points broadens (Lee, Song, and Kim 2012).

\subsection{The effect of a corporate-level integration program on cross-selling}

CRS is the financial value that contributes to the firm aside from the brand where the first transaction occurred, and it is regarded as an important early indicator of customer retention as well as the third creation channel for CE (Kumar, George, and Pancras 2008; Venkatesan and Kumar 2004). An empirical study by Lemon and Wangenheim (Lemon and Wangenheim 2009) on a multi-firm partnership program proved that satisfaction with the core brand has positive impact on the usage of affiliated brands, and the purchase amount from affiliated brands has positive impact on the purchase amount from the core brand in the following period, thereby forming a virtual cycle. In the case of a corporate-level integration program, there are many aspects that prove this program contributes to cross-selling. First, if a customer is uncertain about a brand and lacks experience in using it, reliability and confidence act as the keys to trust that lower perceived risks (Moorman 1995). Therefore, if there is high reliability and confidence in the firm that manages the company-wide program, the effect will be to lower the perceived risks of multiple brands within the network that customers have no experience with, thereby exerting positive impact on cross-purchase intention. Moreover, consumer sentiments exposed frequently to multiple brands in the affiliation network that increase the possibility of acquiring rewards by consuming within the network will accelerate cross-purchasing. In addition, considering the characteristics of consumer behavior that tries to move up the point of reward acquisition by increasing purchases as that point comes closer (Kivetz, Urminsky, and Zheng 2006), and the ceiling effect, in which consumption in specific categories is limited, brands with diverse categories will resolve the ceiling effect, while acting as an alternative to accelerate the point of reward acquisition, thereby stimulating cross-purchasing.

\section{Empirical analysis}

\subsection{Data}

In order to empirically analyze the $\mathrm{CE}$ creation effect of a company-wide loyalty program integration, this study examines a specific loyalty program in South Korea in which eight brands participate. Before integration, each brand individually managed its own loyalty program, and consumers who joined each program could only earn and redeem points with the specific brand. However, after integration, 
consumers were allowed to earn and redeem points with any of the brands in the unified program. The empirical study focuses on top four brands. As shown in Table 2, after integration, the top four brands made up 86\% of the total sales, out of the eight brands that participated in the program.

This study conducts a comparative analysis of equivalent cases by comparing the differences in $\mathrm{CE}$ among similar consumer groups that made their first purchases before and after program integration. Individual purchase records of 12,000 customers for each brand were tracked. The sample for the present study was obtained through stratified sampling, which categorized the customer ratings into three classes (high/ middle/low) individually, based on the total purchase amounts approximately one year and three months from when the integrated loyalty program was introduced. The final sample consisted of 12,000 customers (4,000 per class). Overall, representativeness was ensured by verifying the total purchase amounts per class as well as the demographic similarities (e.g., gender and age). The customer percentage in Table 2 shows the ratio of customers' subscription channel through each brand before and after integration, based on the number of customers subscribed through each brand. The decrease in brand A (Films) and brand D (Online shopping) after integration is expected to be related to the relative decrease in the number of brand $B$ (Food \& Beverage) subscribers.

The data observation period was 24 months before integration and 16 months after integration. As shown in Fig. 1, the target and period for individual CLV measurement, before and after integration were set as follows: pre-integration CLV was measured at the end of March 2010, which was 6 to 12 months after the first purchase was made by each of the 1,200 customers between April and September 2009; and post-integration CLV was measured at the end of September 2011, which was 6 to 12

〈Table 2〉 Status of the brands participating in the company-wide integration program

\begin{tabular}{|c|c|c|c|c|c|c|}
\hline \multirow[b]{2}{*}{ Brand } & \multirow[b]{2}{*}{ Category } & \multirow{2}{*}{$\begin{array}{l}\text { Launch of } \\
\text { stand-alone } \\
\text { program before } \\
\text { integration }\end{array}$} & \multicolumn{2}{|c|}{ Customer percentage } & \multicolumn{2}{|c|}{ Average amount per purchase } \\
\hline & & & $\begin{array}{c}\text { Pre- }^{-} \\
\text {integration }\end{array}$ & $\begin{array}{c}\text { Post- } \\
\text { integration }\end{array}$ & $\begin{array}{c}\text { Pre- }^{-} \\
\text {integration }\end{array}$ & $\begin{array}{c}\text { Post- } \\
\text { integration }\end{array}$ \\
\hline $\mathrm{A}$ & Films & May 2001 & $52 \%$ & $38 \%$ & $\$ 17$ & $\$ 25$ \\
\hline B & Food and beverage & Mar. 2009 & $10 \%$ & $27 \%$ & $\$ 28$ & $\$ 38$ \\
\hline $\mathrm{C}$ & Drug stores & Jan. 2000 & $10 \%$ & $11 \%$ & $\$ 14$ & $\$ 27$ \\
\hline $\mathrm{D}$ & Online shopping & Aug. 2001 & $14 \%$ & $10 \%$ & $\$ 107$ & $\$ 127$ \\
\hline
\end{tabular}

Notes:

- Customer percentage: Number of customers joined to the loyalty program via each brand / Total number of customers

- Average amount per purchase: Average purchase amount for each brand during the observation period 
months after the first purchase was made by each of the 1,200 customers between October 2010 and March 2011. The demographic characteristics were equivalent in the two groups, thus verifying the comparative analysis of equivalent cases $(p<.01)$.

In order to verify the brands in which the integration effect occurred, this study categorized the brand characteristics as follows: 1) preintegration customer base size; 2) product diversity (one category vs. multiple categories); and 3) channel type (online vs. offline). Next, it compared the contribution of each $\mathrm{CE}$ creation channel (i.e., ACQ, RET, and CRS). Finally, the customers were divided into new and existing customers at the brand level. Then, we examined the differences in CE, ACQ, RET, and CRS between pre- and post-integration as well as conducted a regression analysis to investigate which individual characteristics (e.g., the pre-integration average purchase amount, transaction period, recency, and number of brands purchased) among the variables explained the differences in individual buying behaviors and had an impact on the integration effect.

\subsection{Measurement of CLV}

The measurement of CLV can vary based on whether the transaction is associated with a customer contract that can easily predict a point of potential customer churn. For example, in contracts involving telecommunications or financial products or subscriptions, it is common to estimate the CLV using the customer retention rate predicted by the contract transaction data and survival analysis techniques (Bolton 1998). Conversely, in non-contractual setting, such as retail stores, movie theaters, or travel agencies, it is more difficult to predict a point of customer churn (Hoppe and Wagner 2014). Thus, under

〈Figure 1〉 The target and period for individual CLV measurement, before and after integration

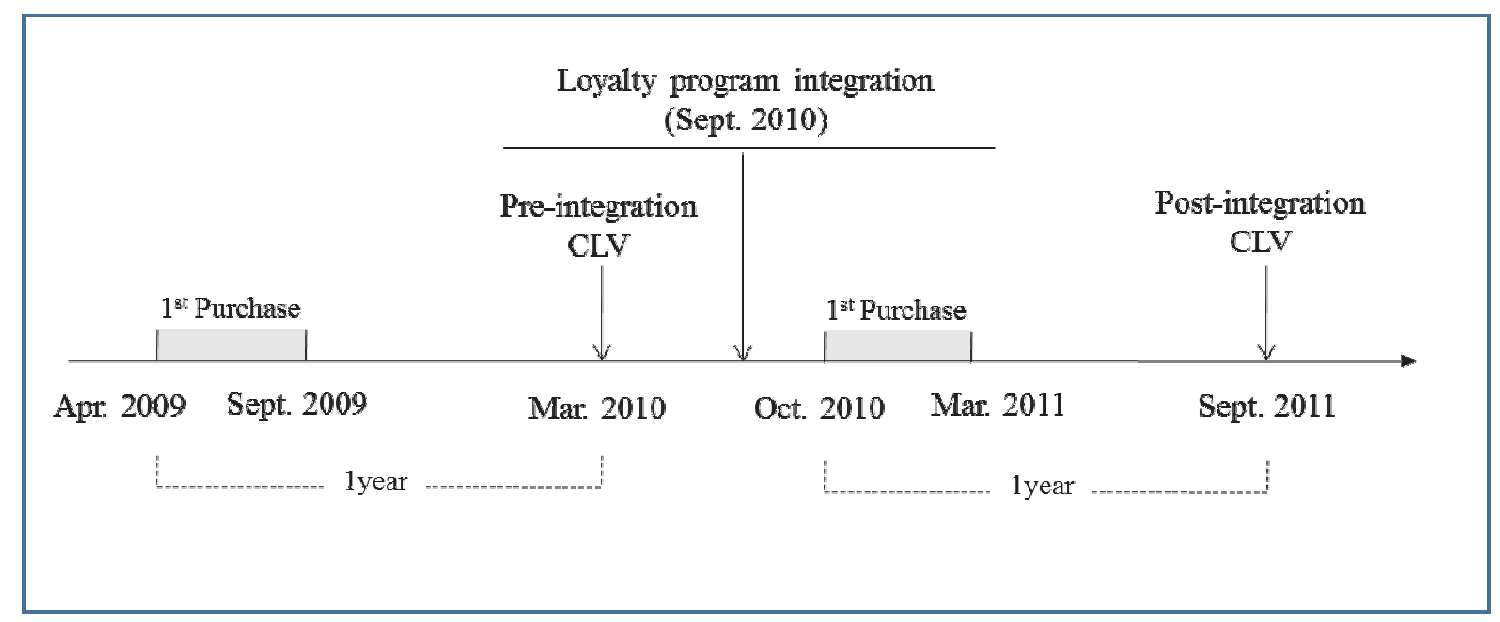


the assumption that the buying behavior of the past will be similar to that in the future, the CLV is calculated by estimating the expected purchase frequency $E(x)$ and expected purchase amount $E(m)$ in the future.

The probability distribution uses recency $(R)$, frequency $(F)$, and monetary value $(M)$ data, and the buying behavior of the past, as shown in Formula (4). Here, the typical probability models used in predicting expected purchase frequency include the Pareto/Negative Binomial Distribution (Pareto/NBD) model (Schmittlein, Morrison, and Colombo 1987), the BetaGeometric/Negative Binomial Distribution (BG/ NBD) model (Fader, Hardie, and Lee 2005), and the Beta-Geometric/Beta-Bernoulli (BG/ BB) model (Fader, Hardie, and Shang 2010). The Normal/Normal model (Schmittlein and Peterson 1994) and the Gamma/Gamma model (Colombo and Jiang 1990) are commonly used in predicting expected purchase amounts. ${ }^{1)}$

$$
\begin{aligned}
C L V_{i t}= & \sum_{j=t}^{\infty}(1+d)^{-(j-t)} \\
& {\left[E(x)_{i t} * E(m)_{i t} * C M-F C\right] }
\end{aligned}
$$

$C L V_{i t}$ : customer $i$ 's lifetime value at time $t$

$d$ : discount rate

$E(x)$ : expected purchase frequency

$E(m)$ : expected purchase amount

CM: contribution margin

FC: fixed costs
The data is left-censored on April 2009, since the last release of the stand-alone brand program (among the observed brands) occurred in March 2009. Accordingly, the data from April 2009 to February 2010 was used in model implementation, which targeted 1,303 customers who made their first purchase between April 2009 and September 2009. In addition, we compared the predicted performances per analysis model of six months (prediction_1) before integration (from March to August 2010) and that of six months (prediction_2) after integration (from October 2010 to February 2011) (see Fig. 1). To measure individual CLV, it was necessary to select the optimum model suitable for predicting the expected purchase frequency and amount, which is the sub-model that estimates CLV. In selecting the optimum model for predicting the expected purchase frequency, the Pareto/NBD, BG/NBD, and $\mathrm{BG} / \mathrm{BB}$ models were used, whereas for predicting the expected purchase amount, the Normal/ Normal and Gamma/Gamma models were employed.

The findings show that the performance of the $\mathrm{BG} / \mathrm{BB}$ model was more accurate in terms of the implementation period of the expected purchase frequency, whereas the BG/NBD model was more accurate in terms of the expectation period. As for the expected purchase amount, the Normal/Normal model was more

1) Yoo et al. (2012) details the characteristics and differences of CLV measurement methods. 
(1) For expected purchase frequency

\begin{tabular}{c|c|c|c|c|c|c|c|c}
\multicolumn{3}{c|}{ In-Sample Fit (Log Likelihood) } & \multicolumn{3}{|c|}{ Prediction_1 $\left(x^{2}\right.$ Stat.) } & \multicolumn{3}{c}{ Prediction_2 $\left(x^{2}\right.$ Stat.) } \\
\hline Pareto/NBD & BG/NBD & BG/BB & Pareto/NBD & BG/NBD & BG/BB & Pareto/NBD & BG/NBD & BG/BB \\
\hline-26614.1 & -26614.1 & -26445.1 & 4.297 & 4.296 & 4.602 & 27.183 & 27.183 & 27.555 \\
\hline
\end{tabular}

(2) For expected purchase amount

\begin{tabular}{c|c|c|c|c|c}
\multicolumn{2}{c|}{ In-Sample Fit (MAPE) } & \multicolumn{2}{c|}{ Prediction_1 $\left(x^{2}\right.$ Stat.) } & \multicolumn{2}{c}{ Prediction_2 $\left(x^{2}\right.$ Stat. $)$} \\
\hline Gamma/Gamma & Normal/Normal & Gamma/Gamma & Normal/Normal & Gamma/Gamma & Normal/Normal \\
\hline 63.705 & 53.198 & 35906.907 & 27606.778 & 80432.482 & 72945.373 \\
\hline
\end{tabular}

Notes:

- Bold: Best model

- MAPE: I(real value-expected value)/real valuel*100

- The smaller the number, the better the predictive power.

accurate in both the implementation and prediction periods. Therefore, this study selected the BG/ NBD model and the Normal/Normal model for the empirical analysis (see Table 3).

\section{Results}

\subsection{Integration effect of the loyalty program at the corporate-level}

As a result of integrating the loyalty program at the corporate-level, $\mathrm{CE}$ increased by $12 \%$ compared with its pre-integration level. The detailed assets that contributed to this increase were earned values, which included the first purchase amounts of any new customers, and the cross-selling values from the cross-purchasing of brands other than the ones that the customers first purchased. Fig. 2-1 represents the increase and composition ratio of $\mathrm{CE}, \mathrm{ACQ}$, RET, and CRS post-integration vs. pre-integration. According to the figure, $\mathrm{CE}$ increased by approximately $12 \%$, after the integration of the loyalty program at the corporate-level. The increase among the detailed assets that formed CE showed that CRS increased by 56\% and ACQ increased by $44 \%$ after integration, whereas RET decreased by $14 \%$, all of which indicate that the $\mathrm{CE}$ increase after integration was due to contributions from the $\mathrm{CRS}$ and $\mathrm{ACQ}$ values. After conducting an independent samples t-test to evaluate statistical significance, it was found that the differences in CE, ACQ, RET, and CRS values (before and after integration) were statistically significant, as shown on Fig. $2-1 \quad(p<.05)$. 
Three implications can be drawn from this analysis. First, the company-wide integration of a loyalty program is effective in diversifying customer acquisition channels. The 44\% increase in ACQ value post-integration is based on the fact that Brand A's acquisition channel, with the lowest average purchase amount, decreased to $39 \%$ after integration. In contrast, the acquisition percentages of the three other brands, with relatively high average purchase amounts, were evenly distributed (Brand B: 40\%; Brand C: 15\%; and Brand D: 6\%), thus confirming that the ACQ value shift is caused by an increase in the first purchase amount. This is also a result of the diversification of customer acquisition channels and the increased customer convenience of expanded membership channels, regardless of the channel through

〈Figure 2-1〉 The increase and composition ratio of CE, ACQ, RET, and CRS (pre-integration vs. post-integration)

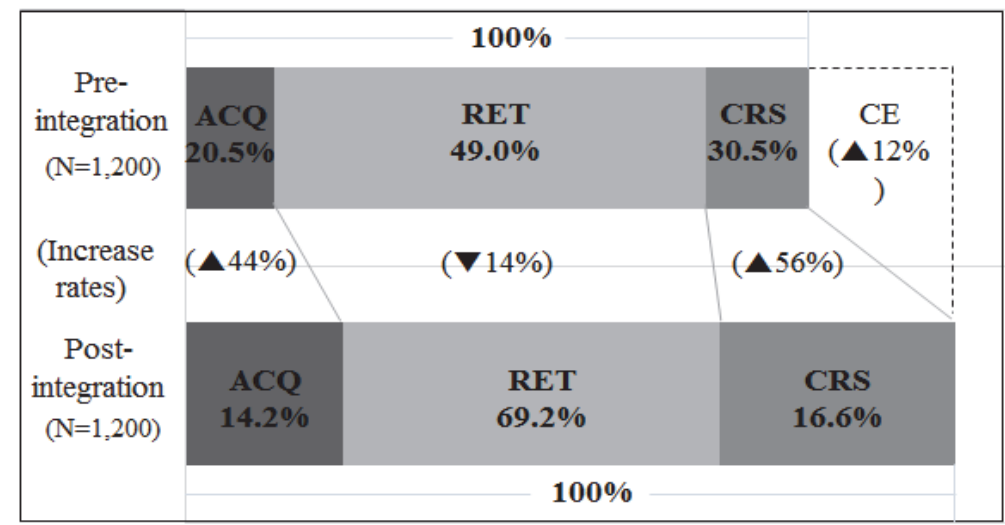

〈Figure 2-2〉 Per capita CE and the contributions of ACQ, RET, and CR (pre-integration vs. post-integration)

\begin{tabular}{|c|r|r|r|r|r|r|}
\hline \multirow{2}{*}{$\begin{array}{c}\text { Customer } \\
\text { Values }\end{array}$} & \multicolumn{2}{|c|}{$\begin{array}{c}\text { Pre-integration } \\
(\mathbf{N}=\mathbf{1 , 2 0 0})\end{array}$} & \multicolumn{2}{|c|}{$\begin{array}{c}\text { Post-integration } \\
(\mathbf{N}=\mathbf{1 , 2 0 0})\end{array}$} & $\begin{array}{c}\text { Rate of } \\
\text { increase }\end{array}$ & P-value \\
\cline { 2 - 7 } & Mean & \multicolumn{1}{|c|}{ STDV } & \multicolumn{1}{|c|}{ Mean } & STDV & <nit USD \$> \\
\hline CE & 104.06 & 94.12 & 133.50 & 145.90 & $28 \%$ & 0.00 \\
\hline ACQ & 22.56 & 37.89 & 40.14 & 76.01 & $78 \%$ & 0.00 \\
\hline RET & 65.77 & 64.31 & 57.54 & 79.33 & $-13 \%$ & 0.03 \\
\hline CRS & 15.73 & 39.18 & 35.82 & 64.21 & $128 \%$ & 0.00 \\
\hline
\end{tabular}


which they join. This proves that the intention of consumers (including those that did not participate in the individually managed programs) to join the integrated program increased after the program was introduced. The integrated program at the corporate-level has the effect of diversifying brand experiences for consumers.

Second, from the perspective of each brand, the company-wide integration program is less effective than a stand-alone program in terms of customer retention. This shows that consumers participating in a stand-alone program have different consumption behaviors than those participating in a company-wide integration program. In the case of a stand-alone program, since there is no way to obtain rewards but to increase transaction volume with the focal brand, customers generally focus more on dealing with the brand. On the other hand, in an integrated program, customers show a different consumption behavior in which they accumulate points and obtain rewards by increasing overall transaction volume within the affiliation network. This result is similar to the findings of Lee, Song, and Lim (2012), which verified the low customer retention effect of single brand programs compared to point affiliation programs. This implies that, from the perspective of customer retention, standalone programs are more effective than partnership programs.

Third, as we expected, cross-selling has been identified as the biggest reason for the increase in post-integration customer equity compared to before. This implies that the integration of loyalty programs increases the company's marketing efficiency. While a single program operation only promotes the brand to the customer, an integrated program may promote several brands to the customer. These benefits provide the customer with the opportunity to be exposed to multiple brands, resulting in cross-selling effects.

\subsection{Role of Brand Characteristics}

Fig. 3-1 presents the CE composition ratio for each brand (before and after integration) and the $\mathrm{CE}$ increase per brand after integration. The CE contribution of Brand A, which plays the role of the new customer acquisition channel before integration, is $71.1 \%$. However, as the channels shift after integration, Brand A's CE contribution becomes significantly lower, at approximately $21.7 \%$. On the other hand, the $\mathrm{CE}$ of Brand $\mathrm{B}$, which is the food service brand with a high average amount per purchase and product diversity, and Brand D, which is the home shopping brand, tripled and contributed to the company-wide CE increase after integration. Fig. 3-1 shows the result of the independent samples t-test regarding the differences in the average CLV $(p<.01)$, and the detailed asset increase rates before and after integration. The average CLV increase per brand before and after integration includes a statistically significant 
difference, while only CRS has a statistically significant difference in the CRS increase of all four brands. The ACQ value shows a significant difference only in Brand A, whereas the RET value shows no significant difference pre- and post-integration for all of the brands. Thus, the $\mathrm{CE}$ increase in the brands can vary and such differences are due to the detailed asset contributions.
Based on these results, what characteristics of the brands control the effect of integration? In order to answer this question, the brand characteristics are classified into the number of customers before integration, level of product diversity, and store channel characteristics. Fig. 4-1, 2, 3 presents the changes in detailed assets per customer before and after integration, based on the characteristics of all aforementioned

〈Figure 3-1〉 The composition ratio of CE, ACQ, RET, and CRS for each brand and the CE increase per brand after integration (pre-integration vs. post-integration)

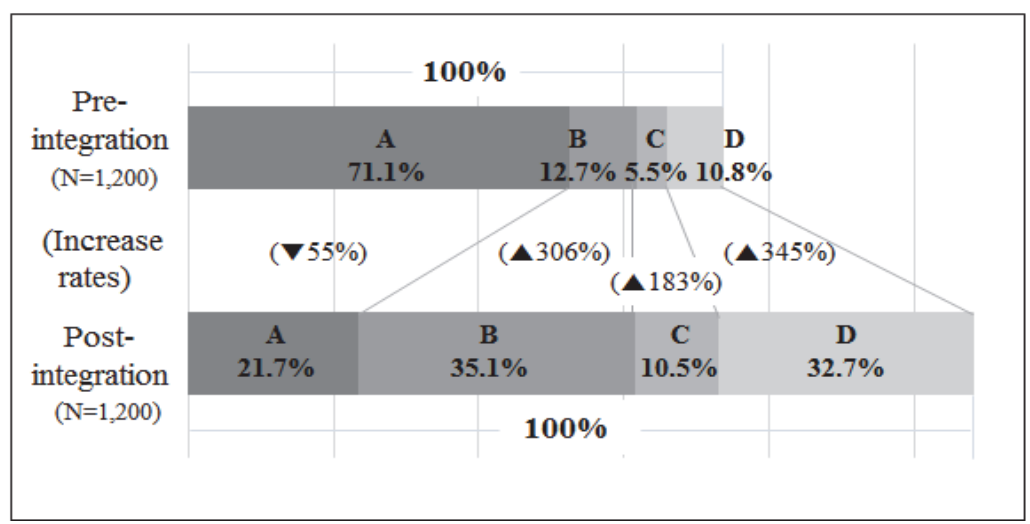

〈Figure 3-2〉 The increase rates of the average CLV of each brand and the detailed asset after integration

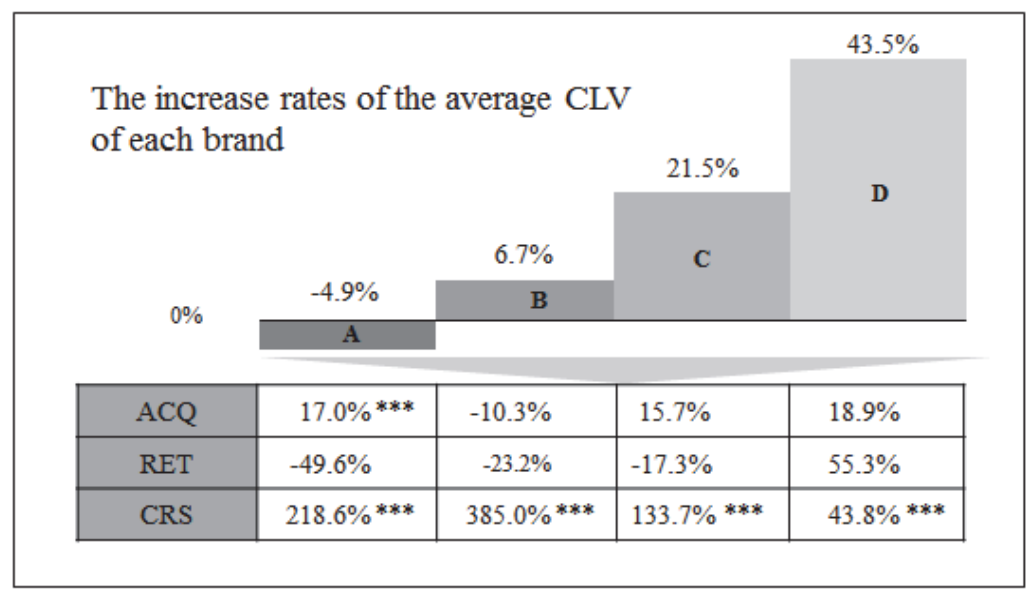


brands. In Fig. 4-1, the ACQ value is the amount paid at the point of the first purchase, with no difference before and after integration. Hence, it is excluded from the scope of the comparative analysis of contributions. In addition, the results of comparing Brand $\mathrm{A}$, which included at least $60 \%$ of the customers before integration, and Brand $\mathrm{C}$, which had less than $15 \%$, show that the composition ratio of the RET value and the CRS value of the two brands were similar, with a slight increase in cross-selling contribution post-integration. This confirms that, based on the size of the customer base before integration, there is no significant detailed asset change after integration. Conversely, the level of product diversity shows a significant difference in the change of detailed assets after integration (Fig. 4-2). Brand A, which only provides one product item, shows a remarkable increase in the percentage of CRS value after integration compared with Brand $\mathrm{B}$, which provides various products. This finding supports the fact that there is a change in consumption behavior after integration.

Finally, in Fig. 4-3, comparison of the three brands that operate offline stores to Brand D, which strictly engages in online distribution, shows that the brick-and-mortar business contributes to the CRS value increase in other brands post-integration, whereas the online distribution business shows an increase in $\mathrm{CE}$ through RET in the relevant brand before and after integration. Brand D shows a 345\%
〈Figure 4-1〉 Size of customer base before integration (Big size vs. Small size)

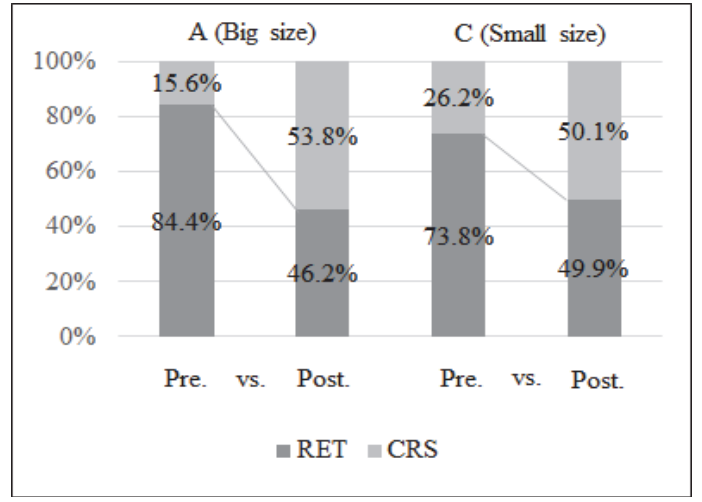

〈Figure 4-2〉 The level of product diversity (Low level vs. High level)

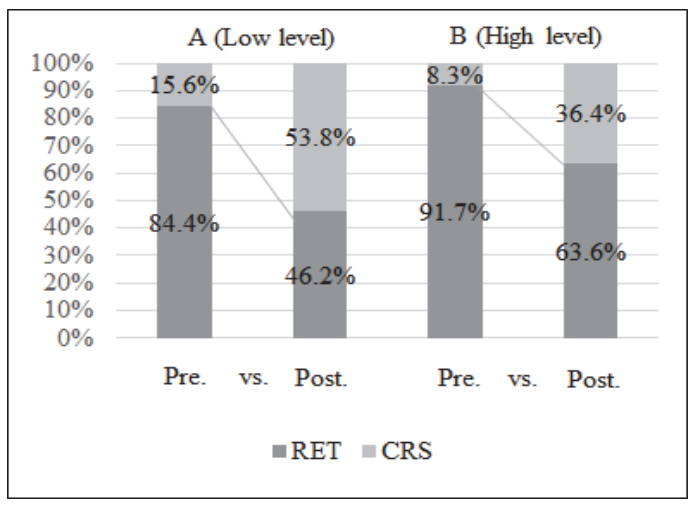

〈Figure 4-3〉 Sales channel characteristics (Offline vs. Online)

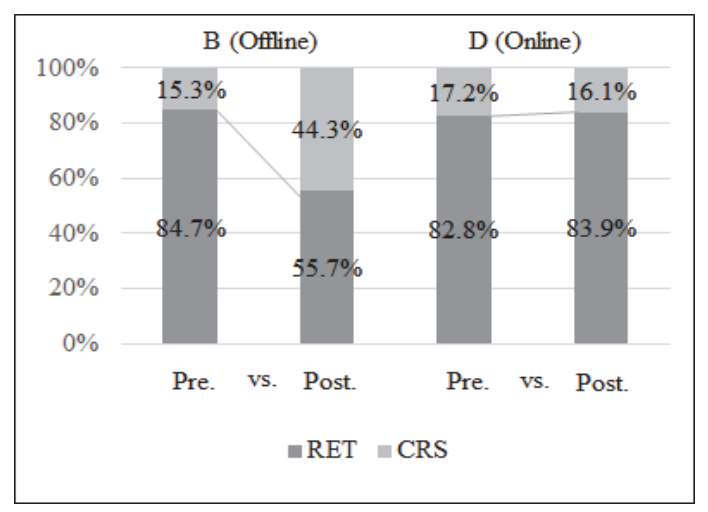


increase in $\mathrm{CE}$ after integration, thus presenting a significant increase in the CRS value per consumer in terms of per capita CLV (Fig. 4-3). However, from the perspective of the overall brands, the RET value makes the greatest contribution to the increase of $\mathrm{CE}$ in Brand D after integration. This finding shows that there is a difference in behavior between online and offline customers.

Based on the results above, the roles of the brands in increasing CE through a companywide integration loyalty program can be summarized as follows. First, brands that offer only limited items supply customers to other brands. In this regard, consumers using Brand A maximize utility through the loyalty program by maintaining their relationship with the brand purchased before integration. However, there is a change in consumption behavior after integration, with consumers aiming to maximize utility by expanding cross-purchasing into other brands. It is important to note that, despite the fact that Brand A had the largest customer base before integration, the brand did not contribute to an increase in CE after integration. In fact, it was the only brand in which the $\mathrm{CE}$ decreased at the brand level.

At the corporate-level, brands that handle a single product, such as Brand A, play an important role in increasing $\mathrm{CE}$ by supplying new customers to affiliated brands after integration. However, this implies that, from the perspective of the brand it-self, maximizing customer retention by managing a stand-alone program is actually more effective in creating brand $\mathrm{CE}$ than participating in a companywide integration program. This implies that not all brands benefit from a company-wide integration program.

Second, brands that manage online stores have a channel barrier compared to brands that manage offline stores; that is, cross-purchasing is not promoted post-integration. The per capital average CLV of the customers of Brand D (the online shopping brand) as well as the CLV increase after integration, were the highest of the four brands. Considering the results of previous studies (Kumar and Venkatesan 2005; Neslin et al. 2006), which argued that CLV increases as a greater variety of channels are used, there is a need for additional research on the factors that may lower channel barriers between online and offline stores as well as marketing efforts by firms to promote the cross-purchasing of online customers with offline brands.

Third, not all brands contribute to the $\mathrm{CE}$ increase of a firm after integration through cross-selling. Instead, some brands create an integration effect through retention based on brand characteristics. The RET percentage of Brand D is significantly high (more than $80 \%$ ) since it is an online shopping channel that provides various items. Thus, consumers can maximize the utility of a company-wide loyalty integration program by promoting cross-purchasing 
within the brand or increasing wallet share.

In sum, the participation in an integration program of online brands with high average purchase amounts, such as Brand D, allows customers to engage with the brand, while the brand further up-sells and cross-sells its other products. In addition, it can increase the CE of the brand, thereby highlighting the benefit of participating in a company-wide integration program. The result suggests that a loyalty program can be an additional control company characteristic factor in the integrative model for the antecedents and consequences of $\mathrm{e}^{-}$ loyalty by Toufaily, Ricard, and Perrien (2013).

\subsection{Role of Customer Characteristics}

In order to examine which consumers contribute to the CE increase after integration, this study first examines the differences in CLV and the detailed asset contributions between existing and new customers before and after integration.
To this end, consumers with transactions in the year before integration (April 2009 to March 2010) are defined as "pre-integration retention customers," and those who make their first transaction in the three months before integration (January to March 2010) are defined as "pre-integration new customers." Likewise, the existing customers in the year after integration (October 2010 to September 2011) are defined as "post-integration retention customers," while those who make their first transaction in the three months after integration (June to September 2011) are defined as "postintegration new customers."

According to Fig. 5, existing customers show a purchasing increase of approximately 10.7\% (from $\$ 88$ before integration to $\$ 97$ after integration), whereas new customers show a four-fold purchasing increase of $441.5 \%$ (from $\$ 36$ before integration to $\$ 198$ after integration). These results show that per capita CLV of postintegration new customers increased significantly.

〈Figure 5〉 The difference in average CLV between retention and new customers

\begin{tabular}{|c|c|c|c|c|c|c|c|}
\hline \multirow{2}{*}{$\begin{array}{l}\text { Customer } \\
\text { Value }\end{array}$} & \multirow{2}{*}{ Group } & \multicolumn{2}{|c|}{ Pre-integration } & \multicolumn{2}{|c|}{ Post-integration } & \multirow{2}{*}{$\begin{array}{c}\text { Increase } \\
\text { rates }\end{array}$} & \multirow{2}{*}{ P-value } \\
\hline & & $\mathrm{N}$ & Mean & $\mathrm{N}$ & Mean & & \\
\hline \multirow{2}{*}{ CLV } & Retention customers & 4,236 & 88,072 & 2,708 & 97,497 & $10.7 \%$ & 0.00 \\
\hline & New customers & 238 & 36,615 & 924 & 198,286 & $441.5 \%$ & 0.00 \\
\hline \multirow[t]{2}{*}{ RET } & Retention customers & 4,236 & 70,659 & 2,708 & 63,131 & $-10.7 \%$ & 0.00 \\
\hline & New customers & 238 & 33,944 & 924 & 153,459 & $352.1 \%$ & 0.00 \\
\hline \multirow{2}{*}{ CRS } & Retention customers & 4,236 & 17,413 & 2,708 & 34,366 & $97.4 \%$ & 0.00 \\
\hline & New customers & 238 & 2,671 & 924 & 44,827 & $1578.3 \%$ & 0.00 \\
\hline
\end{tabular}


Such results also imply that it is important to make efforts to acquire new customers, in addition to attracting existing customers to participate in the integrated program. Moreover, for post-integration existing customers, the RET value decreased by $10.7 \%$ compared to pre-integration, while the CRS value increased by $97 \%$. As for the new customers, the RET value increased by $352.1 \%$, while the CRS value increase by $1,578.3 \%$ compared to preintegration, proving that the CRS value makes a significant contribution to the slight increase in the CLV among post-integration existing customers. On the other hand, the CRS value makes the largest contribution to the four-fold increase of CLVs among new customers as well as the RET value, which also shows a significant contribution.

Next, to verify which customer demographic characteristics and consumption behaviors are factors that explain the post-integration CLV increase, this study analyzed 365 customers with transactions before the integration, who made their first purchases between October 2010 and March 2011. The descriptive statistics of the variables used in this analysis are shown in Table 4. The findings of the correlation analysis show that the correlation among the variables is generally significant. However, the variables with suspected multi-collinearity are not verified, thus proving that there is no problem in applying it to the regression analysis (see Table 5). The result of the regression analysis (see Table 6) shows that the postintegration CLV increase is higher under four conditions: 1) if there is a higher pre-integration average purchase amount; 2) if there is a shorter pre-integration transaction period; and 3) if there is a closer point of final purchase to the integration program launch; and 4) if there is a larger number of brands used before integration. Demographically, females show a greater CLV increase after integration than males, while age is an insignificant variable.

〈Table 4〉 Descriptive statistics

\begin{tabular}{l|c|r|r|r|r|r}
\hline \multicolumn{1}{c|}{ Variables } & \multicolumn{1}{c|}{$\mathrm{N}$} & \multicolumn{1}{c|}{ Mean } & \multicolumn{1}{c|}{ Min. } & \multicolumn{1}{c|}{ Max. } & \multicolumn{1}{c|}{ Total } & \multicolumn{1}{c}{ STD } \\
\hline Difference in CLV (USD) & 365 & 117.00 & -562.52 & $4,069.92$ & 42.70 & 344.40 \\
\hline Average purchase amount (USD) & 365 & 26.80 & 4.00 & 377.15 & 11.57 & 27.04 \\
\hline Transaction period & 365 & 462.05 & 1 & 728 & 199,604 & 228.27 \\
\hline Recency (days) & 365 & 110.21 & 1 & 153 & 47,722 & 41.87 \\
\hline \# of usage brands & 365 & 2.03 & 1 & 4 & 876 & 1.04 \\
\hline Gender (male: 1) & 365 & 0.20 & 0 & 1 & 88 & 0.40 \\
\hline Age & 365 & 32.42 & 19 & 67 & 14,004 & 7.75 \\
\hline
\end{tabular}

Notes:

- Difference in CLV = CLV after integration - CLV before integration

- Recency: The last purchase time 
〈Table 5〉 The correlation table of the regression analysis

\begin{tabular}{l|l|l|l|l|l|l|l}
\hline \multicolumn{1}{c|}{ Variables } & 1 & 2 & 3 & 4 & 5 & 6 & 7 \\
\hline Difference in CLV (USD) & 1.00 & $0.20^{* * *}$ & -0.02 & $0.09^{*}$ & $0.17^{* *}$ & $-0.12^{* *}$ & 0.01 \\
\hline Average purchase amount (USD) & $0.20^{* * *}$ & 1.00 & $-0.10^{* *}$ & -0.06 & $0.13^{* *}$ & 0.04 & $0.20^{* * *}$ \\
\hline Transaction period & -0.02 & -0.10 & 1.00 & $0.56^{* * *}$ & $0.50^{* * *}$ & $-0.1^{* *}$ & $0.09^{*}$ \\
\hline Recency (days) & $0.09^{*}$ & -0.06 & $0.56^{* * *}$ & 1.00 & $0.31^{* * *}$ & -0.03 & 0.05 \\
\hline \# of usage brands & $0.17^{* *}$ & $0.13^{* *}$ & $0.50^{* * *}$ & $0.31^{* * *}$ & 1.00 & $-0.28^{* * *}$ & 0.04 \\
\hline Gender (male: 1) & $-0.12^{* *}$ & 0.04 & $-0.15^{* *}$ & -0.03 & $-0.28^{* * *}$ & 1.00 & $0.15^{* *}$ \\
\hline Age & 0.01 & $0.20^{* * *}$ & $0.09^{*}$ & 0.05 & 0.04 & $0.15^{* *}$ & 1.00 \\
\hline
\end{tabular}

Notes:

- Pearson Analysis, ${ }^{* * *}$-value $<0.01,{ }^{* *}$-value $<0.05,{ }^{*}$-value $<0.10$ (two-tailed)

〈Table 6〉 Results of the regression analysis

\begin{tabular}{|c|c|c|c|c|c|c|c|}
\hline \multirow[t]{2}{*}{ Variables } & \multicolumn{2}{|c|}{$\begin{array}{l}\text { Unstandardized } \\
\text { Coefficients }\end{array}$} & \multirow{2}{*}{$\begin{array}{c}\begin{array}{c}\text { Standardized } \\
\text { Coefficients }\end{array} \\
\beta\end{array}$} & \multirow[t]{2}{*}{$t$} & \multirow[t]{2}{*}{$\mathrm{p}$-value } & \multicolumn{2}{|c|}{ Multicollinearity } \\
\hline & B & S.E & & & & Tolerance & VIF \\
\hline Constant & 50206.245 & 95005.257 & & .528 & .598 & & \\
\hline Average purchase amount & 3.166 & .981 & .178 & 3.227 & .001 & .837 & 1.195 \\
\hline Transaction period & -327.172 & 126.525 & -.174 & -2.586 & .010 & .561 & 1.781 \\
\hline Recency & 1407.428 & 556.158 & .158 & 2.531 & .012 & .657 & 1.522 \\
\hline \# of usage brands & 86369.038 & 42108.651 & .125 & 2.051 & .041 & .690 & 1.449 \\
\hline Gender & -93258.398 & 46624.710 & -.108 & -2.000 & .046 & .868 & 1.153 \\
\hline Age & -1022.880 & 2404.572 & -.023 & -.425 & .671 & .905 & 1.105 \\
\hline Adj. $R^{2}$ & \multicolumn{2}{|c|}{0.07} & \multicolumn{2}{|c|}{$\mathrm{F}$ ( $\mathrm{p}$-value) } & \multicolumn{3}{|c|}{$5.67(.00)$} \\
\hline
\end{tabular}

Notes:

- Dependent variable: Difference in CLV $=$ CLV value after integration-CLV value before integration

- Average purchase amount: Total purchase amount before integration/Total purchase frequency before integration

- Transaction period: The last purchase time before integration - The first time before integration

- Recency: The last purchase time

- \# of usage brands: The number of transaction brands before integration

- Gender: Male $=1$, Female $=0$

\section{Conclusion}

\subsection{Academic and Managerial Implications}

The academic contributions of this study can be summarized as follows. First, this study provides a starting point of relevant research by analyzing the synergy effects of a companywide loyalty program integration, which has been overlooked to research, although mostly holding companies manage their own umbrella loyalty program. This study finds that the channel that creates the main company-wide integration program $\mathrm{CE}$ value is inter-brand cross-selling, and it clarifies that the synergy 
effects of integration are asymmetric, according to brand characteristics. Such findings are significant in that the synergy creation process among firm departments diversifying their businesses can be examined in terms of consumer consumption behaviors. The study contributes a better theoretical understanding the interdependence theory how individual brands in relationships influence each other (Bantham, Celuch, and Kasouf 2003).

Second, it is unusual to find research that fully examines the $\mathrm{CE}$ creation channel from all three aspects of ACQ, RET, and CRS, despite the fact that $\mathrm{CE}$ is the ultimate long-term performance indicator for marketing activities including loyalty programs, while simultaneously it is the marketing management object (Dorsh and Carlson 1996). Hence, the fact that this study comprehensively examines $\mathrm{CE}$, the three channels that create $\mathrm{CE}$, and the CLV at the individual-level, provides various implications to related studies in the future.

Third, this study measures the long-term performance of a loyalty program using threeyear transaction records. Long-term performance measurement is highly important since a loyalty program is a marketing activity with an effect that may disappear over the long run, even if there is initial short-term success. In this regard, according to Allaway, Berkowitz, and D’Souza (2003) and Liu (2007), there are cases in which there is short-term performance, but the effect is not maintained over the long run. However, there are limited studies that tracked the changes of consumer behaviors over the long run by using transaction records of more than one year.

Previous studies (Kivetz, Urminsky, and Zheng 2006: Lal and Bell 2003) have conducted longitudinal analyses using transaction data of approximately 12 weeks. However, considering the purchase cycle, this raises the question of whether long-term purchasing behavioral changes can be examined with only a certain period of data. The present study provides a theoretical contribution in that it empirically supports the research findings of Lee, Song, and Kim (2012), who argued that the effects on the customer retention of partnership loyalty programs will be less than that of stand-alone brand programs. Furthermore, the success of a loyalty program is directly affected by the perspective of the firm (O’Brien and Jones 1995). Thus, it is highly important to measure and constantly manage the performance of a loyalty program.

This study demonstrates the most practical significance in that it offers a method of measuring the performance of a loyalty program in terms of $\mathrm{CE}$, which is particularly important from a long-term viewpoint. In addition, it presents an opportunity to understand the necessity of management strategies for each channel by determining how a company-wide loyalty integration program contributes to $\mathrm{ACQ}$, RET, and CRS, all of which are the main channels that create CE. Third, this study 
verified that the effects can vary among brands that participate in a company-wide integration program, and that the creation method of the synergy effects can also vary according to brand characteristics. Accordingly, it shows that there is a need to search for ways to maximize performance at the corporate-level as well as to allow each brand to participate in an integration program. Finally, the methodology used in this study, which can measure individual acquisition value, retention value, and cross-selling value, will help determine the most suitable customer

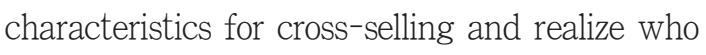
can be retained for a longer period of time (Kumar, George, and Pancras 2008).

\subsection{Limitations and Future Research}

The ideal research method for measuring the effect of integration on $\mathrm{CE}$ is to adopt a program evaluation method that compares an experimental group that participates in the integration and a control group that does not participate in the process. However, the loyalty program to be empirically analyzed includes limitations in that it is difficult to track the changes in the transaction behaviors of the latter group. Hence, it is difficult to fully clarify the overall treatment effect of integration. To make up for this limitation, pre- and postintegration $\mathrm{CE}$ of customers with experience in joining three or more brand programs before integration should be compared as an additional analysis. If post-integration CE increases, despite a similar number of brands used before and after integration, this can be analyzed as an effect of integration. A review of this also validates that the issue of structural change, which can only be systematically tracked after integration, can seem like an integration effect, despite the same pattern of transactions before and after integration.

This study examined a group of customers that used three or more brands from April 2009 to March 2010 and a group of customers who used less than three brands, after which it predicted the CLV one year from the end of March 2010. Subsequently, actual sales generated by the relevant customers were compared by conducting an independent samples t-test. The results showed that the actual sales from customers who used three or more brands increased by approximately $\$ 144$, which was more than that of the group that used less than three brands ( \$66 increase). Thus, this supports the fact that the measured CLV difference is an effect of integration $(p<.01)$. According to the results of the empirical analysis, online brand consumers make relatively fewer cross-brand purchases compared to offline brand consumers. Considering the fact that crosspurchasing is a main factor that increases customer retention and equity (Kumar, George, and Pancras 2008), it is implied that conducting research on factors that can lower the channel barrier between online and offline cross-purchasing 
is necessary in order to create such synergy. In light of this implication, it is necessary to examine what factors may promote customer convenience if online and offline channel brands form partnerships. The analysis data used in this study was $76 \%$ for women and $24 \%$ for men, with an overwhelming percentage of women. This reflects general gender distribution of loyalty programs (Money Today, 2015). However, since the consumption characteristics may differ between women and male consumers, further studies that distinguish them will be necessary.

According to Fig 5., the retention group that joined the single program used the brand similarly ( $\$ 70.6$ vs. \$63.1) and doubled the cross-purchase ( $\$ 17.4$ vs. \$34.3) after integration. On the other hand, when comparing a customer who joined a single program for a specific brand before integration and a customer who joined the program that included multiple brands, the increase level of repurchase and cross-buying is ( \$33.9 vs. \$153.4) and ( \$2.6 vs. \$44.8). It can be seen that customers who subscribe to the integrated program do much more repetitive purchases and cross purchases. This cannot rule out the possibility of an intensive promotion to new customers in the integration program, rather than existing customers who have already joined the program and agree to use the integrated personal information in the integrated program.

To this end, since the empirical analysis was only conducted on a company-wide integration program of a specific firm, it is difficult to generalize the results. It is true that the majority of previous studies on partnership loyalty programs have only analyzed specific programs, due to the difficulty in securing the research data of multiple programs. However, there is a need for research on more diverse cases in order to achieve theoretical systemization.

〈Received April 10. 2018〉

〈Accepted January 14. 2019〉

\section{References}

Money Today, July, 17, 2015. "Women in their 20s are most obsessed with scoring points" (https://news.joins.com/article/18245743)

Blattberg, R., Getz, G., \& Thomas, J. S. (2001). Customer Equity: Building and Managing Relationships as Valuable Assets. Boston, MA: Harvard Business School Press.

Rust, R. T., Zeithaml, V. A., \& Lemon, K. N. (2000). Driving Customer Equity: How Customer Lifetime Value is Reshaping Corporate Strategy, Free Press.

Bantham, J. H., Celuch, K. G., \& Kasouf, C. C. (2003). A perspective of partnerships based on interdependence and dialectical theory. Journal of Business Research, 56(4), 265274.

Allaway, A. W., Berkowitz, D., \& D’Souza, G. (2003). Spatial diffusion of a new loyalty 
program through a retail market. Journal of Retailing, 79(3), 137-151.

Avery, J., Steenburgh, T. J., Deighton, J. \& Caravella, M. (2012). Adding Bricks to Clicks: Predicting the Patterns of CrossChannel Elasticities Over Time. Journal of Marketing, 76(3), 96-111.

Berger, P. D., \& Nasr, N. (1998). Customer Lifetime Value: Marketing Models and Applications. Journal of Interactive Marketing; 12(1), 17-30.

Blattberg, R. C., Malthouse, E. C., \& Neslin, S. A. (2009). Customer Lifetime Value: Empirical Generalizations and Some Conceptual Questions. Journal of Interactive Marketing, 23(2), 157-168.

Bolton, R. N. (1998). A Dynamic Model of the Duration of the Customer's Relationship with a Continuous Service Provider: The Role of Satisfaction. Marketing Science, 17(1), 45-65.

Bolton, R. N., Lemon, K. N., \& Verhoef, P. C. (2004). The Theoretical Underpinnings of Customer Asset Management: A Framework and Propositions for Future Research. Journal of the Academy of Marketing Science, 32(3), 271-292.

Capizzi, M. T., \& Ferguson, R. (2005). Loyalty trends for the twenty-first century. Journal of Consumer Marketing, 22(2), 72-80.

Chatterjee, P. (2012). The role of varying information quantity in ads on immediate and enduring cross-media synergies. Journal of Marketing Communications, 18(3), 217240.

Colombo, R., \& Jiang, W. (1999). A stochastic RFM model. Journal of Interactive Marketing, 13(3), 2-12.

Dorsh, M. J., \& Carlson, L. (1996). A Transaction Approach to Understanding and Managing Customer Equity. Journal of Business Research, 35(3), 253-264.

Dorotic, M., Fok, D., Verhoef, P. C., \& Bijmolt, T. H. A. (2011). Do vendors benefit from promotions in a multi-vendor loyalty program? Marketing Letter, 22(4), 341-356.

Evanschitzky, H., Ramaseshan, B., Woisetschlager, D. M., Richelsen, V., Blut, M., \& Backhaus, C. (2012). Consequences of customer loyalty to the loyalty program and to the company. Journal of the Academy Marketing Science, 40(5), 625-638.

Fader, P. S., Hardie, B. G. S. \& Lee, K. L. (2005). Counting Your Customers the Easy Way: An Alternative to the Pareto/ NBD Model. Marketing Science, 24(2), 275-84. Fader, P. S., Hardie, B. G. S., \& Shang, J. (2010). Customer-Base Analysis in a Discrete-Time Noncontractual Setting. Marketing Science, 29(6), 1086-1108.

Furinto, A., Pawitra, T., \& Balqiah, T. E. (2009). Designing competitive loyalty programs: How types of program affect customer equity. Journal of Targeting, Measurement and Analysis for Marketing, 17(4), 307-319. Goold, M., \& Campbell, A. (1998). Desperately 
seeking synergy. Harvard Business Review, 76(5), 131-143.

Gupta, S., \& Lehmann. D. R. (2003). Customers as assets. Journal of Interactive Marketing, 17(1), 9-24.

Gupta, S., \& Zeithaml, V. (2006). Customer Metrics and Their Impact on Financial Performance. Marketing Science, 25(6), 718-739.

Gupta, S., Hanssens, D., Hardie, B., Kahn, W., Kumar, V., Lin, N., Ravishanker, N., \& Sriram, S. (2006). Modeling Customer Lifetime Value. Journal of Service Research, 9(2), 139-155.

Hoppe, D., \& Wagner, U. (2014). The role of lifetime activity cues in customer base analysis. Journal of Business Research, 67 (5), 983-989.

Johnson, K. (1998). Choosing the right program. Direct marketing, 61(2), 36-45.

Kivetz, R., Urminsky, O., \& Zheng, Y. (2006). The Goal-Gradient Hypothesis Resurrected: Purchase Acceleration, Illusionary Goal Progress, and Customer Retention. Journal of Marketing Research, 43(1), 39-58.

Kopalle, P. K., \& Neslin. S. A. (2003). The Economic Viability of Frequent Reward Programs in a Strategic Competitive Environment. Review of Marketing Science, 1(1), 1-39.

Kumar, V., \& Venkatesan, R. (2005). Who are the multichannel shoppers and how do they perform?: Correlates of multichannel shopping behavior. Journal of Interactive Marketing, 19(2), 44-62.

Kumar, V., George, M., \& Pancras, J. (2008). Cross-buying in retailing: Drivers and consequences. Journal of Retailing, 84(1), 15-27.

Lal, R., \& Bell, D. E. (2003). The Impact of Frequent Shopper Programs in Grocery Retailing. Quantitative Marketing and Economics, 1(2), 179-202.

Lee, J. J., Capella, M. L., Taylor, C. R., Luo, M., \& Gabler, C. B. (2014), "The financial impact of loyalty programs in the hotel industry: A social exchange theory perspective. Journal of Business Research, 67(10), 2139-2146.

Lee, J. W., Song, T. H. \& Kim, J. Y. (2012). A Study on the Effects of Inter-firm Coalition Loyalty Programs : Focusing on Customer Acquisition vs. Retention Effects. Journal of the Korean Operations Research and Management Science Society, 38(3), 183-199

Lemon N. K., \& Wangenheim, F. V. (2009). The Reinforcing Effects of Loyalty Program Partnership and Core Service Usage. Journal of Service Research, 11(4), 357-370.

Liu, Y. (2007). The Long-Term Impact of Loyalty Programs on Consumer Purchase Behavior and Loyalty. Journal of Marketing, 71(4), 19-35.

Liu, Y., \& Yang, R. (2009). Competing Loyalty Programs: Impact of Market Saturation, 
Market Share, and Category Expandability. Journal of Marketing, 73(1), 93-108.

Marciukaityte, D., Roskelley, K., \& Wang, H. (2008). Strategic alliances by financial services firms. Journal of Business Research, 62(11), 1193-1199.

Neslin, S. A., Grewal, D., Leghorn, R., Shankar, V., Teerling, M. L., Thomas, J. S., \& Verhoef, P. C. (2006). Challenges and Opportunities in Multichannel Customer Management. Journal of Service Research, 9(2), 95-112.

O’Brien, L., \& Jones, H. (1995). Do Rewards Really Create Loyalty? Harvard Business Review, 73(3), 75-82.

Rumelt, R. P. (1982). Diversification strategy and profitability. Strategic Management Journal, 3(4), 359-369.

Rust, R. T., Ambler, T., Carpenter, G. S., Kumar, V., \& Srivastava, R. K. (2004). Measuring Marketing Productivity: Current Knowledge and Future Directions. Journal of Marketing, 68(4), 76-89.

Rust, R. T., Lemon, K. N., \& Zeithaml, V. A. (2004). Return on Marketing: Using Customer Equity to Focus Marketing Strategy. Journal of Marketing, 68(1), 109-127.

Schmittlein, D. C., Morrison, D. G., \& Colombo, R. (1987). Counting Your Customers: Who Are They and What Will They Do Next? Management Science, 33(1), 1-24.

Yoo, S., Hanssens, D. M., \& Kim, H. (2012). Marketing and the evolution of customer equity of frequently purchased brands. Working Paper.

Toufaily, E., Ricard, L., \& Perrien, J. (2014). Customer loyalty to a commercial website: Descriptive meta-analysis of the empirical literature and proposal of an integrative model. Journal of Business Research, 66 (9), 1436-1447.

Varadarajan, P. R. (1986). Horizontal Cooperative Sales Promotion: A Framework for Classification and Additional Perspectives. Journal of Marketing, 50(2), 61-73.

Varadarajan, R. \& Rajaratnam D. (1986). Symbiotic Marketing Revisited. Journal of Marketing, 50(1), 7-17.

Venkatesan, R., \& Kumar, V. (2004). A Customer Lifetime Value Framework for Customer Selection and Resource Allocation Strategy. Journal of Marketing, 68(4), 106-125.

Verhoef, P. C., \& Donkers, B. (2001). Predicting customer potential value an application in the insurance industry. Decision Support Systems, 32(2), 189-199.

Walter, J., Lechner, C., \& Kellermanns, F. W. (2007). Knowledge transfer between and within alliance partners: Private versus collective benefits of social capital. Journal of Business Research, 60(7), 698-710.

Yi, Y., \& Jeon, H. (2003). Effects of Loyalty Programs on Value Perception, Program Loyalty, and Brand Loyalty. Journal of the Academy of Marketing Science, 31 (3), 229-240. 